\author{
Heinrich Volker Groesdonk \\ Matthias Heringlake
}

\section{The kidney in acute renal failure: innocent bystander, victim or still a suspect?}

Received: 17 November 2009

Accepted: 19 November 2009

Published online: 5 January 2010

(C) Copyright jointly hold by Springer and ESICM 2009

This editorial refers to the article available at: doi:10.1007/s00134-009-1740-9.

H. V. Groesdonk (®)

Intensive Care Unit, Department of Thoracic and Cardiovascular Surgery, University of Saarland, Kirrbergerstrasse,

Homburg, Saarland, Germany

e-mail: heinrich.groesdonk@uks.eu; groesdonk@web.de

Tel.: +49-6841-1632011

Fax: +49-6841-1632005

M. Heringlake

Department of Anesthesiology, University of Lübeck, Ratzeburger Allee, Lübeck, Germany

Despite great progress in critical care, acute renal failure (ARF) is a frequent and fatal complication contributing significantly to morbidity and mortality among critically ill patients [1]. The incidence of ARF in intensive care units ranges from 3 to $25 \%$ depending on the criteria applied, underlining the problem of more than 30 definitions. Today the two widely accepted classification systems are the RIFLE criteria and the staging system for acute kidney injury (AKI) as established by the Acute Dialysis Quality Initiative (ADQI) and the Acute Kidney Injury Network (AKIN), respectively [2, 3]. Regardless of modern renal replacement therapies and promising preclinical and clinical treatment trials, ARF-related hospital mortality ranges between 25 and $80 \%$ [2-4]. This unacceptably high mortality as well as increasing costs of critical care treatment exerts pressure to develop a better understanding of the underlying pathology of this disease and to generate new therapeutic strategies with the potential to attenuate ARF. Although the pathophysiology of ARF is not fully understood, there is general agreement that in several clinical situations renal hypoperfusion and a concomitant lowering of the glomerular filtration rate (GFR), induced by a decrease in systemic and/or renal perfusion pressure, are hallmarks of the genesis of ARF [5-10].

In this issue of Intensive Care Medicine, Dr. Saotome and co-authors further our knowledge of the significance of different states of renal hypoperfusion on the formation of ARF [11]. The authors conducted a study of a ewe model with various degrees of renal hypoperfusion. This was realized solely by reducing the renal blood flow to $25-80 \%$ of baseline. Additionally, they achieved severe, sustained subtotal renal hypoperfusion. Summarizing their findings, 25,50 or $75 \%$ impairment of renal blood flow for 30 min was not associated with extended loss of renal function. During $2 \mathrm{~h}$ of $80 \%$ hypoperfusion, urine output decreased from 80 to $17 \mathrm{ml}$, and creatinine clearance from 32 to $3 \mathrm{ml} / \mathrm{min}$, while plasma creatinine increased from 103 to $132 \mu \mathrm{mol} / \mathrm{l}$. Restoration of normal renal blood flow induced brief hyperemia before all measured variables returned to normal within $8 \mathrm{~h}$ and remained normal for the following $72 \mathrm{~h}$, leading to the conclusion that, "unlike total ischemia, severe hypoperfusion alone is insufficient to induce subsequent persistent AKI."

At first glance, these findings are in strict contrast to what we have learned about hypoperfusion-associated AKI-commonly referred to as acute pre-renal failureso far [5-10], raising the question of whether we should start to re-write our pathophysiology and critical care textbooks. This is clearly not the case. However, this elegant study broadens our horizon regarding the impact of extrarenal factors on kidney function during renal circulatory dysfunction. 
It is important to realize that-with a few exceptions like atheroembolic kidney disease-the experimental model employed is highly different from the renal hypoperfusion states we are confronted with in clinical practice and from the experimental renal failure models used in the past [12]. It is well established that renal hypoperfusion accompanied by low mean arterial pressure is ultimately associated with the classical signs of pre-renal AKI, often referred to as "acute tubular necrosis" (ATN) [5-10]. In contrast, the model applied in the present study resembles the one-kidney Goldblatt model used to study renal (arterial) hypertension [13]. And indeed, the authors clearly demonstrate that reduced renal blood flow resulted in increased systemic mean arterial pressure (MAP), something rarely encountered in a systemic hypoperfusion state. This is highly suggestive that it is not the low flow to the kidney but the concomitant circulatory state that translates renal hypoperfusion either into overt ATN (i.e., AKI) or allows renal function to recover immediately if renal blood flow is restored again, at least within the time frame tested in the present study.

This information is not really new, but rarely recognized in the current literature. Almost 30 years ago, Gorfinkel and coworkers-while comparing the effects of hemorrhagic and cardiogenic shock on renal function and histopathology in a conscious dog model-showed that renal blood flow and the histological signs of ATN were completely different during both shock states (despite a comparable mean arterial pressure and cardiac index). Interestingly, renal function was somewhat preserved during cardiogenic shock, and this renoprotective effect was abolished by cardiac denervation and thus mediated by cardiopulmonary receptors [14].

More recently, Douzinas and colleaques have shown that increasing arterial blood pressure during hemorrhagic shock ameliorates post-shock kidney dysfunction [15], suggesting a comparable role of high pressure baroreceptors in this setting. Both observations are not astonishing, since the sympathetic nervous and efferent renal nerves as well as catecholamines and the reninangiotensin-aldosterone system (RAAS) play an important role in regulating and distributing renal blood flow as well as the mediating tubular reabsorptive capacity [16].

Studies employing the Goldblatt model have shown that acute reductions in renal blood flow are not only followed by a significant increase in the RAAS activity, mediating the observed changes in arterial blood pressure, but also a counterregulatory increase in natriuretic peptides $[17,18]$. This may be important for kidney function, since these hormones have been shown to mediate natriuresis and diuresis and are thus capable of modulating the effects of increased RAAS activity.

Unfortunately, Saotome and co-authors [11] did not determine the humoral responses to renal hypoperfusion in this model; however, such analyses may offer important insights into why this specific model of isolated renal low flow behaves so differently from the established models of combined systemic and renal hypoperfusion. This may ultimately help to understand which factors make the difference and which measures should thus therapeutically be addressed in future studies.

Nonetheless, we have to thank the authors for reminding us that the kidney may play different roles during AKI. Additionally, we have to change our attitude about this organ: the kidney may be suspect due to the upregulation of intrarenal mechanisms translating prolonged hypoperfusion into overt ATN, a victim of the extrarenal mechanisms translating systemic hypoperfusion into renal failure, and sometimes only an innocent bystander like in this model. This largely depends on the prevailing circulatory state.

\section{References}

1. Cruz DN, Ricci Z, Ronco C (2009) Clinical review: RIFLE and AKINtime for reappraisal. Crit Care 13:211

2. Bellomo R, Ronco C, Kellum JA, Mehta RL, Palevsky P (2004) Acute renal failure-definition, outcome measures, animal models, fluid therapy and information technology needs: the Second International Consensus Conference of the Acute Dialysis Quality Initiative (ADQI) Group. Crit Care 8:R204-R212

3. Mehta RL, Kellum JA, Shah SV, Molitoris BA, Ronco C, Warnock DG, Levin A (2007) Acute kidney injury network: report of an initiative to improve outcomes in acute kidney injury. Crit Care 11:R31
4. Joannidis M (2007) Acute renal failure 25 years of progress and innovation in intensive care medicine. Medizinische Wissenschaftliche Verlagsgesellschaft, Berlin, pp 43-54

5. Bonventre JV, Weinberg JM (2003) Recent advances in the pathophysiology of ischemic acute renal failure. J Am Soc Nephrol 14:2199-2210

6. Schrier RW, Wang W (2004) Acute renal failure and sepsis. $\mathrm{N}$ Engl $\mathrm{J}$ Med 351:159-169

7. Schrier RW, Wang W, Poole B, Mitra A (2004) Acute renal failure: definitions, diagnosis, pathogenesis, and therapy. J Clin Invest 114:5-14
8. Sutton TA, Fisher CJ, Molitoris BA (2002) Microvascular endothelial injury and dysfunction during ischemic acute renal failure. Kidney Int 62:1539-1549

9. Thadhani R, Pascual M, Bonventre JV (1996) Acute renal failure. N Engl J Med 334:1448-1460

10. Abuelo JG (2007) Normotensive ischemic acute renal failure. N Engl J Med 357:797-805

11. Saotome T, Ishikawa K, May C, Birchell I, Bellomo R (2009) The impact of experimental hypoperfusion on subsequent kidney function. Intensive Care Med. doi: 10.1007/s00134-009-1740-9 
12. Lieberthal W, Nigam SK (2000) Acute renal failure. II. Experimental models of acute renal failure: imperfect but indispensable. Am J Physiol Renal Physiol 278:F1-F12

13. Barger AC (1979) The Goldblatt memorial lecture. Part I: experimental renovascular hyptertension. Hypertension 1:447-455

14. Gorfinkel HJ, Szidon JP, Hirsch LJ, Fishman AP (1972) Renal performance in experimental cardiogenic shock. Am J Physiol 222:1260-1268
15. Douzinas EE, Andrianakis I, Livaditi O, Paneris P, Tasoulis M, Pelekanou A, Betrosian A, Giamarellos-Bourboulis EJ (2008) The level of hypotension during hemorrhagic shock is a major determinant of the post-resuscitation systemic inflammatory response: an experimental study. BMC Physiol 8:15

16. Hollenberg NK, Fisher ND, Price DA (1998) Pathways for angiotensin II generation in intact human tissue: evidence from comparative pharmacological interruption of the renin system. Hypertension 32:387-392
17. Verburg KM, Freeman RH, Villarreal D, Brands MW (1987) Atrial natriuretic factor in dogs with one-kidney, one-clip Goldblatt hypertension. Am J Physiol 253:H1623-H1627

18. Wolf K, Kurtz A, Pfeifer M, Hocherl K, Riegger GA, Kramer BK (2001)

Different regulation of left ventricular ANP, BNP and adrenomedullin mRNA in the two-kidney, one-clip model of renovascular hypertension. Pflugers Arch 442:212-217 